\title{
Changes in Electrocardiogram from Inferior Myocardial Infarction to Anterior Myocardial Infarction
}

\author{
Aslı Yasemen Savaş ${ }^{1}$, Nurşah Başol ${ }^{1}$, Fatih Altunkaş², Halil Ibrahim Damar ${ }^{2}$ \\ 'Department of Emergency Medicine, Gaziosmanpaşa University School of Medicine, Tokat, Turkey \\ 2Department of Cardiology, Gaziosmanpaşa University School of Medicine, Tokat, Turkey
}

\begin{abstract}
We describe a patient who developed acute chest pain and ST-segment elevation in the inferior leads on electrocardiography. In his control electrocardiography after $15 \mathrm{~min}$, ST-segment elevation was observed in the anterior leads. Cardiac catheterization showed that there was wraparound left anterior descending artery and an occlusion in the proximal region. The occlusion was resolved by typical ballooning. To our knowledge, simultaneous ST elevations in anterior and inferior leads have been reported in the literature; however, in our case, with serial electrocardiographic (ECG) records, we realized that inferior ST-segment elevation altered to anterior ST-segment elevation. This indicates the importance of serial ECG records in emergency departments to explain the mechanism.
\end{abstract}

Keywords: Myocardial infarction, wrap, anterior, inferior

\section{Introduction}

Myocardial infarction (MI) results in necrosis of the myocardial muscle due to the occlusion of coronary arteries. Acute occlusion of the left anterior descending coronary artery (LAD) generally results in ST-segment elevations in precordial leads and reciprocal ST-segment depression in inferior leads (1). However, it is sometimes difficult to correlate electrocardiographic (ECG) findings and the infarct-related region. Here we describe a rare case of simultaneous anterior and inferior MI due to the occlusion of "wrapped LAD."

\section{Case Presentation}

A 67-year-old man was admitted to the emergency department with chest and left arm pain. He had primer hypertension for 3 years and he was taking an anti-hypertensive agent but had no history of coronary artery disease. He was not a smoker, and there was no family history of coronary artery disease. His blood pressure was $130 / 80 \mathrm{mmHg}$, and his pulse rate was $87 \mathrm{bpm}$. There were no abnormal findings on physical examination. There were ST-segment elevations in D2, D3, and AVF derivations in his first standard 12-lead ECG (Figure 1), and his troponin and CK-MB levels were $8400 \mathrm{ng} / \mathrm{mL}(0-100 \mathrm{ng} / \mathrm{mL})$ and $102.6 \mathrm{ng} / \mathrm{mL}(0-5 \mathrm{ng} / \mathrm{mL})$, respectively. He was referred to the cardiology clinic with inferior MI. Aspirin (300 mg orally), clopidogrel (300 mg orally), and heparin (5000 IU intravenous) were given to the patient. A percutaneous coronary intervention ( $\mathrm{PCI}$ ) procedure was suggested. In his second ECG that was taken after $15 \mathrm{~min}$, ST-segment elevations were observed between $\mathrm{V} 1$ and $\mathrm{V} 6$ derivations and there were reciprocal ST-segment depressions in D2, D3, and AVF derivations (Figure 2). He then underwent angiography. Wrap around LAD and occlusion of the ostial region of LAD were detected (Figure $3 a, b)$. In addition, there was $30 \%$ occlusion of the circumflex artery (Cx). The lesion was crossed with a 3-5 mm soft guide wire and predilated with Cross rail $20 \times 15 \mathrm{~mm}$ balloons (Alvimedica, Turkey). Then, a coronary stent was placed. Angiography resulted in TIMI II flow, and intracoronary aggrastat (tirofiban $\mathrm{HCL}$ ) was given; he was then taken to the coronary care unit his discharge with recovery. The patient was discharged after 5 days, with the prescription of aspirin (100 $\mathrm{mg} /$ day), clopidogrel (75 mg/day), bisoprolol fumarat (5 mg/day), perindopril ( $5 \mathrm{mg} /$ day), and rosuvastatin (40 mg/day).

Written informed consent was obtained from the patient for the publication of this case report and any accompanying images.

This study was presented as a poster at the $1^{\text {st }}$ International Critical Care and Emergency Medicine Congress, 6-8 November 2013, istanbul, Turkey.

Correspondence to: Nurşah Başol e-mail: drnursahbs@hotmail.com

Received: 28.07.2016 Accepted: 21.11.2016

(C) Copyright 2016 by Emergency Physicians Association of Turkey - Available online at www.eajem.com

DOI: 10.5152/eajem.2016.25744 


\section{Discussion}

Twelve-lead ECG is a diagnostic tool that generally shows the right localization of MI based on ST elevation and reciprocal depression. Inferior ST elevation is generally indicative of the occlusion of the right coronary artery (2). It may rarely indicate the occlusion of the left coronary artery (LAD) (3). In 15\% cases of MI with LAD as the culprit vessel, ST elevation in the inferior leads is observed (4). In a previous study, the efficacy of ECG was evaluated for acute MI of the inferior wall and it was suggested that the results from the interpretation of ECG do not change with angiographic findings, despite rare forms of presentations in inferior ST elevation (3). In the presented case, the first ECG record showed the diagnostic findings of inferior $\mathrm{Ml}$; however, after $15 \mathrm{~min}$, the second ECG showed findings of anterior MI. In angiography, wraparound LAD was observed. Changes in

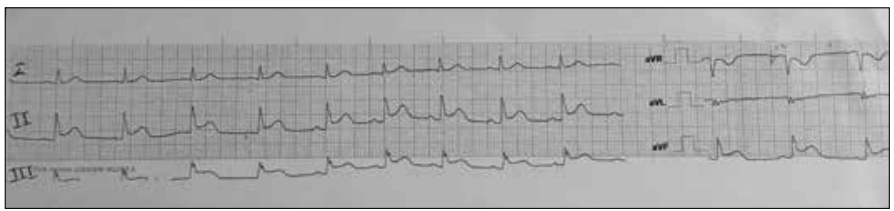

Figure 1. ECG taken during admission

ECG: electrocardiography

Note: We could not obtain chest derivations of the first EKG records

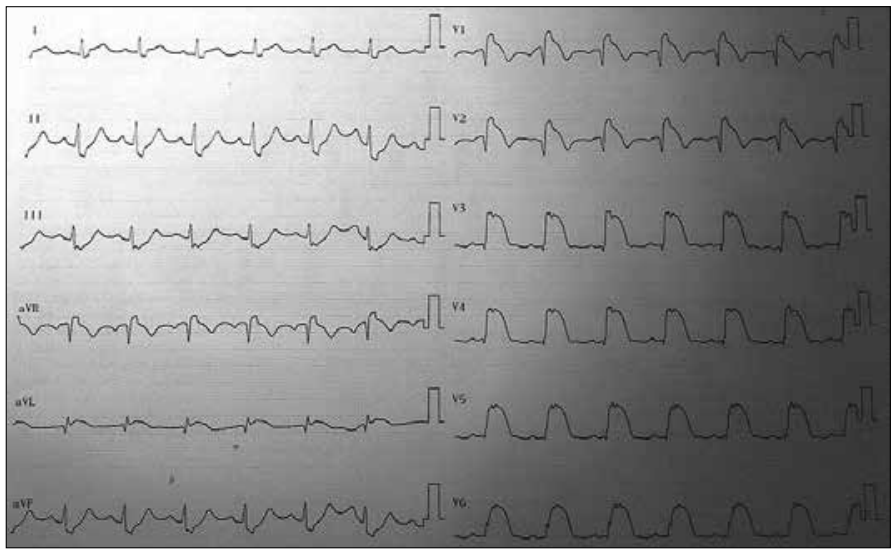

Figure 2. ECG taken after 15 min of admission ECG: electrocardiography

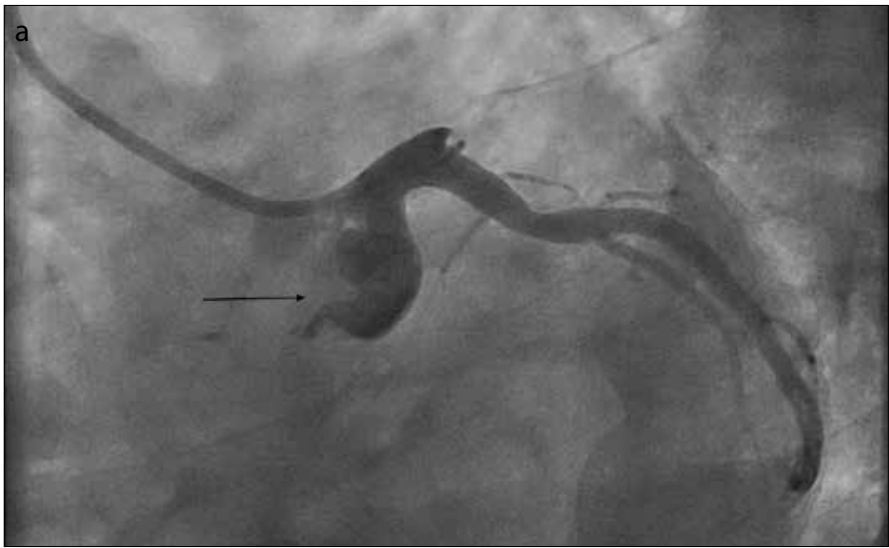

ECG findings may be an indicator of anterior wall infarction. However, angiography was necessary to explain the reason for this alteration in ECG.

Wraparound LAD that extends around the cardiac apex can be anatomically observed in the normal population (5). When LAD wraps around the apex, it supplies blood anteriorly and postero-inferiorly to the myocardium. Thus, concomitant ST elevation could be observed and explained by anterior and inferior wall transmural ischemia simultaneously (6). In addition, it can be rarely observed because of significant collateral flow from LAD to the inferior wall (7). It is suggested that the combination of inferior and anterior ST elevation occurs in case of the occlusion of distal LAD to its major branches. In addition, it has been reported that patients who have combined inferior and anterior ST elevation due to wraparound LAD have a better prognosis than those who have anterior ST elevation (7). Similarly, Sadanandan et al. (5) suggested that combined anterior and inferior ST elevation in ECG records is a sign of limited AMI size and the patients have a better prognosis with isolated anterior ST elevation.

In the presented case, the first ECG record was concordant with inferior $\mathrm{MI}$ and the second showed anterior $\mathrm{MI}$ with reciprocal ST depressions. It may show revascularization of the occlusion of the inferior wall, and then, because of wraparound LAD, transmural ischemia of the anterior wall occurred. It is reported that although transmural ischemia consists of the anterior and inferior wall, ischemia in the inferior wall would disappear because of the force of the injury in the lateral wall (8).

Wraparound LAD caused stenosis of proximal LAD in this case. It is known that the occlusion of proximal LAD has high mortality and morbidity. In the literature, proximal LAD lesions are named as "widow makers" because of their high incidence of mortality (9). However, Sasaki et al. (10) have suggested that if the patient has wrapped LAD and the location of occlusion is proximal to $\mathrm{D}_{1}, \mathrm{ST}$-segments are elevated in the anterior leads and remain within the isoelectric lines in the inferior leads. In our case, ST-segment elevation in the inferior leads was observed before ST-segment elevation in the anterior leads. Ilia et al. (11) have suggested that patients who have anterior ST elevation due to wraparound LAD have a worse prognosis than those who have isolated proximal LAD occlusion. Other factors may affect the severity of clinical outcome. LAD length is one of the important factors $(12,13)$. There is a relationship between LAD length

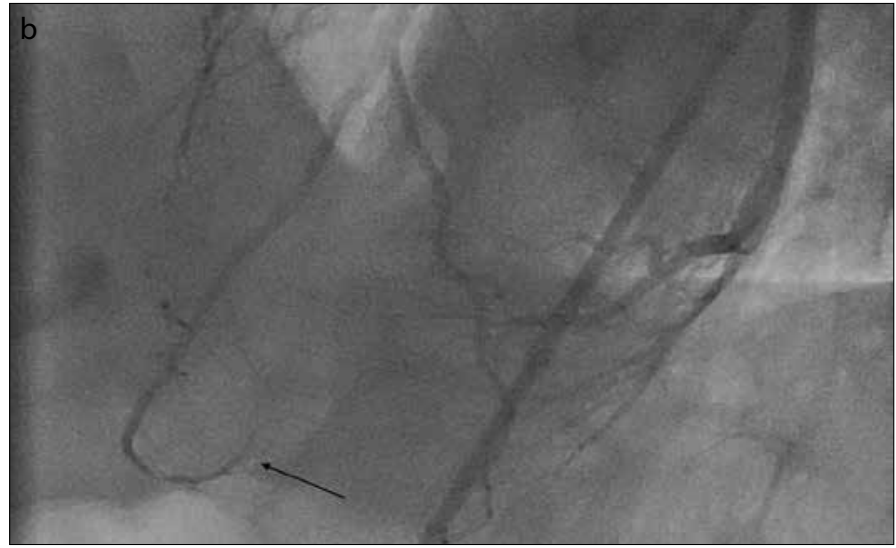

Figure 3. a, b. (a) Occlusion of the ostial region of LAD, (b) Wraparound LAD LAD: left anterior descending coronary artery 
and prognosis. As a result of the greater amount of muscle supplied by a long LAD (in which the vessel wraps around the apex), a greater amount of myocardial necrosis will occur when the vessel occludes. On the other hand, short LADs that do not wrap around the apex have a better prognosis (11).

In the literature, despite conflicts regarding prognosis, simultaneous inferior and anterior ST-segment elevation, due to wraparound $L A D$, has been reported $(5-7,14,15)$. However, there has been an alteration in serial ECG records in the presented case. This indicates the importance of serial ECG records in the emergency department and the efficiency of angiographic findings to explain the mechanism. In addition, it draws attention to wraparound LAD, which can present with unusual ECG records.

Informed Consent: Written informed consent was obtained from patient who participated in this study.

Peer-review: Externally peer-reviewed.

Acknowledgements: It is presented as a poster in $1^{\text {st }}$ International Critical Care and Emergency Medicine Congress, Istanbul, Turkey. Written informed consent was obtained from the patient for publication of this case report and any accompanying images.

Conflict of Interest: No conflict of interest was declared by the authors.

Financial Disclosure: The authors declared that this study has received no financial support.

\section{References}

1. Gibson MC, Krucoff M, Fischell D, Fischell TA, Keenan D, Abueg C, et al. Rationale and design of the AngeLmed for early recognition and treatment of STEMI trial: a randomized, prospective clinical investigation. Am Heart J 2014; 168: 168-74. [CrossRef]

2. Verouden NJ, Barwari K, Koch KT, Henriques JP, Baan J, van der Schaaf $\mathrm{RJ}$, et al. Distinguishing the right coronary artery from the left circumflex coronary artery as the infarct-related artery in patients undergoing primary percutaneous coronary intervention for acute inferior myocardial infarction. Europace 2009; 11: 1517-21. [CrossRef]

3. Kontos MC, Desai PV, Jesse RL, Ornato JP. Usefulness of the admission electrocardiogram for identifying the infarct-related artery in inferior wall acute myocardial infarction. Am J Cardiol 1997; 79: 182-4. [CrossRef]
4. Martinez-Dolz L, Arnau MA, Almenar L, Rueda J, Osa A, Quesada A, et al. Usefulness of the electrocardiogram in predicting the occlusion site in acute anterior myocardial infarction with isolated disease of the left anterior descending coronary artery. Rev Esp Cardiol 2002; 55: 1036-41.

5. Sadanandan S, Hochman JS, Kolodziej A, Criger DA, Ross A, Saelvester R, et al. Clinical and angiographic characteristics of patients with combined anterior and inferior ST-segment elevation on the initial electrocardiogram during acute myocardial infarction. Am Heart J 2003; 146: 653-61. [CrossRef]

6. Aygul N, Ozdemir K, Aydin MU, Duzenli MA. Combined anterior and inferior ST segment elevation during the exercise stress testing. Int J Cardiol 2008; 130: 490-3. [CrossRef]

7. Hofmann U, Schanzenbächer P. Spontaneous dissection of the LAD mimicking inferior myocardial infarction. Herz 2012; 37: 338-41. [CrossRef]

8. Tamura A, Kataoka H, Nagase K, Mikuriya Y, Nasu M. Clinical significance of inferior ST elevation during acute anterior myocardial infarction. $\mathrm{Br}$ Heart J 1995; 74: 611-4. [CrossRef]

9. Schuster EH, Griffith LS, Bulkey BH. Preponderance of acute proximal left anterior descending coronary artery lesions in fatal myocardial infarction: a clinicopathologic study. Am J Cardiol 1981; 47: 1189-96. [CrossRef]

10. Sasaki K, Yotsukura M, Sakata K, Yoshino H, Ishikawa K. Relation of ST-segment changes in inferior leads during anterior wall acute myocardial infarction to length and occlusion site of the left anterior descending coronary artery. Am J Cardiol 2001; 87: 1340-5. [CrossRef]

11. Ilia $\mathrm{R}$, Weinstein $\mathrm{JM}$, Wolak $\mathrm{A}$, Gilutz $\mathrm{H}$, Cafri $\mathrm{C}$. Length of left anterior descending coronary artery determines prognosis in acute anterior wall myocardial infarction. Catheter Cardiovasc Interv 2014; 84: 316-20. [CrossRef]

12. Antoni ML, Hoogslag GE, Boden H, Liem SS, Boersma E, Fox K, et al. Cardiovascular mortality and heart failure risk score for patients after ST-segment elevation acute myocardial infarction treated with primary percutaneous coronary intervention (Data from the Leiden MISSION! Infarct Registry). Am J Cardiol 2012; 109: 187-94. [CrossRef]

13. Kandzari DE, Tcheng JE, Gersh BJ, Cox DA, Stuckey T, Turco M, et al. Relationship between infarct artery location, epicardial flow, and myocardial perfusion after primary percutaneous revascularization in acute myocardial infarction. Am Heart J 2006; 151: 1288-95. [CrossRef]

14. Akpinar I, Arat N, Ozbülbül NI. A case of simultaneous anterior, inferior and right ventricular ST-segment elevation myocardial infarction due to occlusion of the wrapped left anterior descending coronary artery. Turk Kardiyol Dern Ars 2008; 36: 335-7.

15. Sapin PM, Musselman DR, Dehmer GJ, Cascio WE. Implications of inferior ST-segment elevation accompanying anterior wall acute myocardial infarction for the angiographic morphology of the left anterior descending coronary artery morphology and site of occlusion. Am J Cardiol 1992; 69: 860-5. [CrossRef] 